\title{
Índices produtivos e perfil metabólico de ovelhas Santa Inês no pós-parto no nordeste do Pará
}

\section{Production index and metabolic profile of Santa Inês ewes during postpartum in the Northeast of Pará.}

\author{
Elyzabeth da Cruz Cardoso,, Daniel Rocha de Oliveira, ${ }^{*}$ Mário Felipe Alvarez Balaro, ${ }^{*}$ Luiz Fernando Souza Rodrigues,, \\ Felipe Zandonadi Brandão*
}

\begin{abstract}
Resumo
Este estudo relata os índices produtivos, os valores hematológicos e os valores bioquímicos séricos e plasmáticos de ovelhas primíparas e pluríparas da raça Santa Inês durante o período de pós-parto e de lactação com mamada controlada e criadas no município de Igarapé-Açú, estado do Pará. Foram utilizadas 20 ovelhas, divididas igualmente em dois grupos, primíparas e pluríparas. As mensurações foram efetuadas no pós-parto e em tempos predeterminados durante o período de lactação. Índices de famacha, escore corporal e peso foram considerados como índices produtivos. Valores metabólicos foram analisados no sangue total (Volume Globular e hemoglobina), no soro (Proteína total, albumina, globulina, cálcio, fósforo e magnésio) e plasma (glicose, ureia e beta-hidroxibutirado). Os resultados do escore corporal, volume globular, hemoglobina, albumina sérica e ureia plasmática apontaram para a necessidade de pequenos ajustes dos nutrientes na ração, pois, associados ao da forrageira ainda promoveram ligeiros decréscimos nos indicadores metabólicos.

As variações da glicemia foram fisiológicas e não demandaram a utilização das reservas corporais suficiente para promover um aumento na concentração de corpos cetônicos na circulação. Os resultados de $\mathrm{Ca}$ e $\mathrm{P}$ indicaram as variações fisiológicas do parto e da lactação sem demonstrar queda acentuada. Esses resultados quando combinados apontam para a necessidade de um maior ajuste proteico na dieta. Os indicadores metabólicos desmontram estresse da lactação em ovelhas primíparas e pluríparas, e portanto o ajuste nutricional deve ser efetuado para ambos os grupos no inicio, no pico e no final da lactação.
\end{abstract}

Palavras-chave: Amazônia, ovinos, sanidade.

\begin{abstract}
This study reports production indexes, hematological values and plasmatic and serum biochemical values of primiparous and pluriparous Santa Inês sheep during postpartum, with controlled feeding, raised in Igarapé-açu, Pará. Twenty sheep were assigned into two groups: primiparous and pluriparous. Measurements were conducted at postpartum in predetermined times during lactation. Famacha, body and weight scores were considered as production indexes. Metabolic values of total blood (globular volume and hemoglobin); serum (total protein, albumin, globulin, calcium, phosphorus and magnesium) and plasma (glucose, urea and beta-hydroxybutyrate) were analyzed. Results from body scores, globular volume, hemoglobin, serum albumin and plasma urea indicated the need for minor adjustments regarding nutrients in the feed once being associated to forage promote slightly reduction of metabolic indicators. Variations in glycemia were physiological and demanded no use of the body reserved enough to promote the increase of the concentration of ketone bodies in the bloodstream. Results of $\mathrm{Ca}$ and $P$ indicated physiological variations in the delivery and lactation demonstrating no sharp decline. These results, when combined, point out the need of a major protein adjustment in the diet. Metabolic indicators showed stress in the lactation of primiparous and pluriparous sheep; therefore nutritional adjustment should be conducted for both groups at the beginning, peak and end of lactation.
\end{abstract}

Keywords: Amazon, sanity, sheep.

\section{Introdução}

A ovinocultura nacional está passando por um processo de intensificação em decorrência da demanda crescente de carne e produtos derivados da espécie. O estado do Pará vem investindo na cadeia produtiva da espécie ovina, fomentando a intensificação das unidades produtoras na busca da autossuficiência da produção de carne (ARCO JORNAL, 2009). De acordo com a Federação de Agricultura e Pecuária do Pará (FAEPA), em 2008 a ovinocultura paraense reunia 200 mil cabeças. É possível que o rebanho estadual atual seja superior, visto que nem todas as criações estão cadastradas oficialmente, sobretudo os pequenos produtores (FAEPA, 2008).

\footnotetext{
* Faculdade de Veterinária da Universidade Federal Fluminense, Programa de Pós-Graduação em Medicina Vaterinária (Clínica e Reprodução Animal). E-mail para correspondência: elyzabethcardoso@hotmail.com

** Universidade Federal Rural da Amazônia.
} 
Apesar do efetivo ovino no estado ser substancial, existe um grande entrave no manejo alimentar em toda a região amazônica para a criação dessa espécie, sobretudo na região do nordeste paraense, pois ainda utilizam o sistema de criação semiextensivo em pastagens de baixa reserva de nutrientes (Costa Filha, 2002). Neste sentido, os indicadores de produção aparecem como uma ferramenta essencial para dar suporte às mudanças aplicadas dentro dos sistemas de criação existentes.

Em ovinos, os distúrbios do metabolismo do periparto causam perdas econômicas significativas ao produtor, pois podem reduzir a produção leiteira, diminuir o ganho de peso do cordeiro e até mesmo promover a sua morte precoce, que podem ser evitadas utilizando-se o perfil metabólico.

Segundo Contreras (1990), o perfil metabólico compreende uma série de indicadores sanguíneos que permite avaliar o status nutricional dos animais, sobretudo durante a fase reprodutiva e de lactação. Indicadores como glicose, ureia, proteína total, albumina, globulina, cálcio, fósforo, magnésio, escore de condição corporal (ECC), hemoglobina, volume globular e famacha são frequentemente utilizados em vacas durante a lactação e ovinos durante o periparto como um instrumento para diagnóstico de distúrbios metabólicos, deficiências nutricionais e alterações reprodutivas (Brito et al., 2006). Assim, o perfil metabólico ligado ao status nutricional e desempenho reprodutivo tem despertado o interesse de diversos pesquisadores atualmente, enfocando principalmente as maiores exigências nutricionais associadas ao melhor desempenho produtivo dos rebanhos (Peixoto; Osório, 2007).

O presente estudo propõe discutir o comportamento dos índices produtivos, dos valores hematológicos e dos valores bioquímicos séricos e plasmáticos de ovelhas primíparas e pluríparas da raça Santa Inês durante o período de lactação com mamada controlada e criadas em sistema semiintensivo procedente da região do nordeste paraense. E partir dos resultados, diagnosticar possíveis distúrbios metabólicos devido à falhas ou carências no manejo dos animais junto à identificação de indicadores eficientes e de fácil acesso aos produtores que possam ser trabalhadas na rotina e auxiliar no desempenho produtivo do animal.

\section{Material e métodos}

\section{Caracterização da propriedade e dos animais}

O estudo foi desenvolvido no município de Igarapé-Açú, nordeste paraense, microrregião Bragantina. A propriedade utilizada foi escolhida por apresentar ovinos Santa Inês de padrão genético, acompanhados por um técnico no manejo zootécnico e sanitário. As ovelhas em final de gestação foram observadas até a parição e 20 animais foram selecionados de acordo com a categoria, primíparas (10 ovelhas) e pluríparas (10 ovelhas), acompanhadas conforme os seguintes tempos (T): T1: do parto ao 10 dia do pós-parto; T2: do $2^{\circ}$ ao $4^{\circ}$ dia do pós-parto; T3: do $5^{\circ}$ ao 7ํ dia do pósparto; T4: do 8 ao 14을 dia do pós-parto; T5: do 15ำ ao 29ำ dia do pós-parto; T6: do 30ํao 44ํ dia do pós-parto; T7: do 45ํㅡㄴ ao 59 dia do pós-parto e T8: acima de 60 dias de pós-parto.
Os animais foram selecionados segundo exame clínico, sendo que o controle parasitário foi efetuado a partir de exame de fezes para realização do OPG (ovos por grama) pela técnica de Gordon e Whitlock modificada (Ueno, 1998), em três momentos distintos do estudo, ao parto, aos 30 (T6) dias e aos 60 dias (T8) de pós-parto. Todos os animais que apresentaram OPG acima de 500 foram tratados com albendazol oral na dose de $1 \mathrm{~g}$ por quilograma de peso vivo.

As ovelhas foram mantidas em sistema semi-intensivo em pastos cultivados de Panicum maximum cv massai, suplementadas com seis feixes de leguminosa Puerparia phaseodoides e receberam mistura mineral e ração comercial $(87,14 \%$ de matéria seca, $18,27 \%$ de proteína bruta, $8,03 \%$ de resíduo mineral, $6,12 \%$ de fibra bruta e $2,69 \%$ de gordura).

Os cordeiros foram mantidos em sistema de confinamento durante o período experimental sob manejo de mamada controlada, recebendo concentrado e tendo acesso às matrizes às dez horas da manhã e às três horas da tarde.

\section{Pesagem, escore da condição corporal e índice de Famacha}

O peso, a condição corporal e o Índice Famacha das ovelhas foram efetuados nos tempos preestabelecidos, sempre após a colheita do sangue.

As ovelhas foram pesadas individualmente em balanças próprias e avaliadas quanto ao escore corporal considerando as descrições de Suiter (1994) para a espécie ovina em uma escala de 1 (muito magra) a 5 (muito gorda).

Para os índices de Famacha procedeu-se a avaliação da coloração da mucosa ocular com o cartão gabarito da técnica de Famacha em uma escala de 1 (bem corado) a 5 (hipocorado) (Molento et al., 2004).

\section{Colheita de amostras de sangue e análises}

Nos tempos preestabelecidos, o sangue de todas as ovelhas foi colhido através de venopunção jugular, distribuído em dois tubos a vácuo (Vacutainer®), contendo ácido etilenodiamino tetra-acético (EDTA) a 10\% e o outro sem anticoagulante com gel ativador da coagulação para obtenção do soro. O sangue foi colhido sempre pela manhã com os animais em jejum prévio de 12 horas. Em seguida, os animais foram pesados individualmente e avaliados para a condição do escore corporal, considerando as descrições de Suiter (1994) para a espécie ovina.

As análises da hemoglobina e do volume globular foram efetuadas imediatamente após a determinação do índice de Famacha e da condição do escore corporal utilizando-se técnicas de espectrofotometria e de microvolume globular, respectivamente, conforme descrições de Jain (1993). Após análise de VG e HB instilou-se uma gota de fluoreto de sódio para posterior centrifugação e obtenção do plasma. Para obtenção do soro, o sangue colhido foi mantido à temperatura ambiente durante 30 min para ocorrer a retração do coágulo e, em seguida, foi centrifugado.

As análises plasmáticas incluíram a determinação da glicose, ureia, cálcio, fósforo, magnésio e betahidroxibutirato 
e as sorológicas de proteína total, albumina e globulina. Com exceção do betahidroxibutirato, todas as análises foram efetuadas através de técnicas de espectrofotometria utilizando-se kits comerciais (Sistema Labtest de Diagnóstico Clínico), através de espectrofotômetro BioPlus. Os valores da globulina sérica foram obtidos através da subtração daqueles obtidos para proteína total e albumina. A dosagem do betahidroxibutirato foi realizada pelo método enzimático cinético UV (Randox) utilizando o Analisador Bioquímico Automatizado Liasys.

\section{Análises estatísticas}

Para a análise estatística de variância utilizou-se o método de mínimos quadrados tendo o teste $F$ como base para verificar a significância das variáveis estudadas. O modelo experimental usado foi o delineamento inteiramente casualizado considerando dez repetições (animais), sendo os tratamentos arranjados em parcelas divididas, com os grupos (uníparas e pluríparas) estudados nas parcelas e nos tempos (oito observações feitas ao longo do tempo) considerados como subparcelas. Para a comparação das médias foi utilizado o teste de Tukey. Foram calculados os coeficientes de correlação de Pearson entre os pares de variáveis estudadas. As aplicações dos testes foram feitas ao nível de $5 \%$ de probabilidade.

Todas as análises estatísticas seguiram no programa NTIA, versão 4.2.1, de outubro de 1995, desenvolvido pela Embrapa, Campinas-SP.

\section{Resultados e discussão}

O resultado do teste $\mathrm{F}$ das variáveis estudadas encontra-se descrito na Tabela 1. Esses resultados consideram que, nas condições amazônicas estudadas, existiram três tipos de indicadores. O primeiro tipo a ser considerado, é aquele relacionado com o número de partos existentes da ovelha (volume globular, hemoglobina e índice Famacha). O segundo tipo de indicador é aquele que apresenta um comportamento diferente ao longo da lactação, independentemente do número de partos da ovelha (peso, escore da condição corporal, proteína total e albumina séricas, ureia plasmática e cálcio e fósforo sérico). O terceiro e último indicador está relacionado com o período de lactação e ao número de partos da ovelha (globulina, glicose e magnésio).

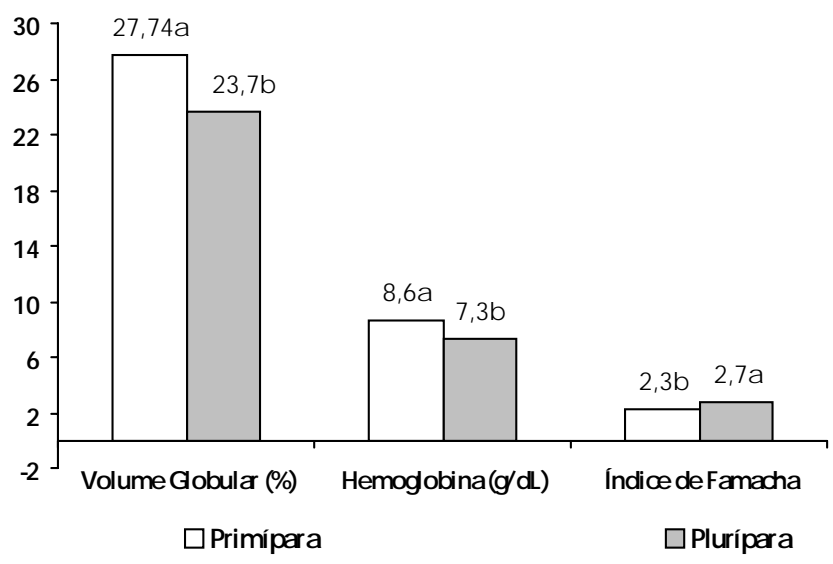

Figura 1: Volume globular, hemoglobina e famacha de ovelhas primíparas e pluríparas da raça Santa Inês, durante o período de lactação, com mamada controlada e criadas no município de Igarapé-Açú, estado do Pará. Agosto a outubro de 2009. Letras diferentes na mesma variável indicam diferença significativa pelo teste de Tukey a $5 \%$.

Gonzalez et al. (2000) ressaltam que o aumento da demanda metabólica induz o aumento compensatório da concentração do VG e da HB e muito embora não se tenha aferido a quantidade de leite produzida pelas ovelhas em lactação no presente estudo, é possível que este fator tenha influenciado as concentrações dessas duas variáveis. Segundo Silva e Lobo (2003), animais de primeira cria apresentam

\section{Volume globular (VG), hemoglobina (HB) e índice Famacha}

O teste de Tukey $(\mathrm{P}<0,05)$ revelou que as concentrações do volume gobular, da hemoglobina e do índice de Famacha foram superiores nas ovelhas primíparas (Figura 1).
Tabela 1: Análise de variância para peso, escore da condição corporal, famacha, volume globular, hemoglobina, proteína sérica total, albumina e globulina séricas, glicose, ureia e betahdroxibutirato plasmático, e cálcio, fósforo e magnésio séricos estudadas durante o período de lactação com mamada controlada e criadas no município de Igarapé-Açú, estado do Pará. Agosto a outubro de 2009

\begin{tabular}{|c|c|c|c|c|c|c|c|}
\hline $\begin{array}{l}\text { Fonte } \\
\text { de Variação }\end{array}$ & $\begin{array}{c}\text { Grupo } \\
(\mathrm{G})\end{array}$ & $\begin{array}{c}\text { Resíduo } \\
\text { a } \\
\end{array}$ & $\begin{array}{c}\text { Tempo } \\
(\mathrm{T})\end{array}$ & $\mathrm{G} \times \mathrm{T}$ & $\begin{array}{c}\text { Resíduo } \\
\text { b }\end{array}$ & $\begin{array}{l}\text { Média } \\
\text { geral }\end{array}$ & $\begin{array}{l}\text { CV } \\
(\%)\end{array}$ \\
\hline Peso & NS & 177,8 & ** & NS & 5,63 & 39,91 & 5,95 \\
\hline ECC & NS & 0,24 & ** & NS & 0,03 & 3,01 & 5,48 \\
\hline Famacha & ** & 0,59 & ** & NS & 0,46 & 2,51 & 27,17 \\
\hline Volume Globular & ** & 21,9 & ** & NS & 9,19 & 25,72 & 11,78 \\
\hline Hemoglobina & ** & 2,36 & ** & NS & 1,83 & 7,96 & 17,01 \\
\hline Proteína sérica total & NS & 6,45 & ** & NS & 0,27 & 6,55 & 7,97 \\
\hline Albumina sérica & NS & 0,28 & ** & NS & 0,07 & 2,41 & 10,97 \\
\hline Globulina sérica & NS & 5,16 & ** & * & 0,25 & 4,13 & 12,02 \\
\hline Glicose plasmática & NS & 302,49 & ** & ** & 171,38 & 63,35 & 20,66 \\
\hline Ureia plasmática & NS & 268,28 & ** & NS & 67,11 & 23,61 & 34,7 \\
\hline BHB plasmático & NS & 2,29 & NS & NS & 3,27 & 5,33 & 33,9 \\
\hline Cálcio sérico & NS & 5,60 & ** & NS & 2,65 & 10,21 & 15,93 \\
\hline Fósforo sérico & NS & 7,37 & ** & NS & 1,43 & 4,88 & 24,48 \\
\hline Magnésio sérico & ** & 9,63 & ** & * & 0,19 & 2,44 & 4,88 \\
\hline
\end{tabular}

* Significativo a $5 \%$ de probabilidade ** Significativo a $1 \%$ de probabilidade NS - Não significativo produtividade leiteira inferior quando comparados àqueles com mais de uma lactação, e nesses casos, é necessário oferecer um maior aporte de nutrientes para as fêmeas pluríparas. Considerando que o controle parasitário dos animais do presente estudo foi permanente, o déficit nutricional existente possa ter sido o fator mais provável para que as 
ovelhas pluríparas tenham apresentado baixas concentrações de VG e HB. Portanto, o estresse da lactação mais acentuado nas ovelhas pluríparas contribuiu para que essa categoria tivesse os valores mais críticos no VG, HB e Famacha.

Del Valle, Witner e Hervé (1983) correlacionaram as variações da composição sanguínea de ovelhas da raça Romney Marsh, no pré e no pós-parto, com o estado nutricional e concluíram que o volume globular (VG) e a hemoglobina (HB) diminuíram quando os requerimentos nutricionais aparentemente não foram preenchidos.

As médias de VG das ovelhas primíparas e pluríparas foram inferiores aquelas verificadas por Brito et al. (2006), entre 34,0 a $39,5 \%$. Os valores médios de hemoglobina também ficaram abaixo dos limites recomendados por Gonzalez et al. (2000), que admitem como normalidade para a espécie, valores entre 9,0 e 13,0 $\mathrm{g} / \mathrm{dL}$.

\section{Peso, escore da condição corporal, proteína total, albumina, ureia, cálcio e fósforo}

Hübner (2008) relatou que após o parto, o peso é restituído de forma gradativa. Esse fato não ocorreu no presente estudo e o peso das ovelhas foi diminuindo ao longo da lactação (Figura 2). Após 60 dias de lactação, as ovelhas não conseguiram atingir o peso ideal de reprodução recomendado para raça $(40 \mathrm{~kg})$; contudo, o peso observado foi bastante próximo ao recomendado $(38,41 \mathrm{~kg})$.

Segundo Suiter (1994), o escore da condição corporal é modulado pelo balanço energético aos quais os animais estão sujeitos durante a lactação e em muitos casos, comprova o balanço negativo existente. No presente trabalho, o escore da condição corporal ficou discretamente abaixo do considerado ideal para a reprodução (3) nos tempos finais de lactação (Figura 2).
Kaneco, Harvey e Bruss (1997) para a espécie. No entanto, a albumina sérica apresentou modificações condizentes com o pico de lactação. Entre o $30^{\circ}$ ao $44^{\circ}$ dia do pós-parto (T6) os valores foram menores do que os valores dos tempos iniciais de lactação (T1, T2 e T3). Segundo Greenwood et al. (2000) e Moura Filho et al. (2005), as necessidades nutricionais são expressivamente superiores durante a lactação, em especial durante o momento de maior produção.

Segundo Gonzalez et al. (2000), a concentração de ureia sérica é um reflexo direto e imediato das quantidades de azoto proteico ingerido e sua redução é condicionada por um aporte proteico inapropriado, assim como a diminuição na absorção, devido a lesões na mucosa gastrintestinal (Ribeiro et al., 2004 e Alencar et al., 2007). Ao observar a concentração da ureia plasmática das ovelhas nos tempos 5 e 6 (Figura 3), isto é, entre o 15 e 44 dias do pós-parto, os valores estiveram abaixo da normalidade considerada por Kaneco, Harvey e Bruss (1997) e certamente o aporte alimentar deficiente condicionou essa redução.

O cálcio sérico $(\mathrm{Ca})$ sofreu variações ao longo da lactação (Figura 4) e os valores mais baixos foram observados do $8^{\circ}$ ao 14ํ dia do pós-parto (T4). De acordo com Mundim et al. (2007), durante a curva produtiva leiteira a síntese do leite promove alterações na quantidade de cálcio sérico devido às diferenças no volume produzido, e essa demanda precisa ser muito acentuada para que o mecanismo de regulação desse elemento não seja capaz de mantê-lo dentro do intervalo considerado ideal. O decréscimo observado foi provavelmente gerado pela demanda exigida, porém foi compensado pelo mecanismo de regulação deste elemento após o $14^{\circ}$ dia de lactação. Durante todo o período de lactação a concentração do cálcio manteve-se dentro dos valores de referência estipulados por Gonzalez et al. (2000), compreendido no intervalo de $7,4 \mathrm{a} 13 \mathrm{mg} / \mathrm{dL}$.
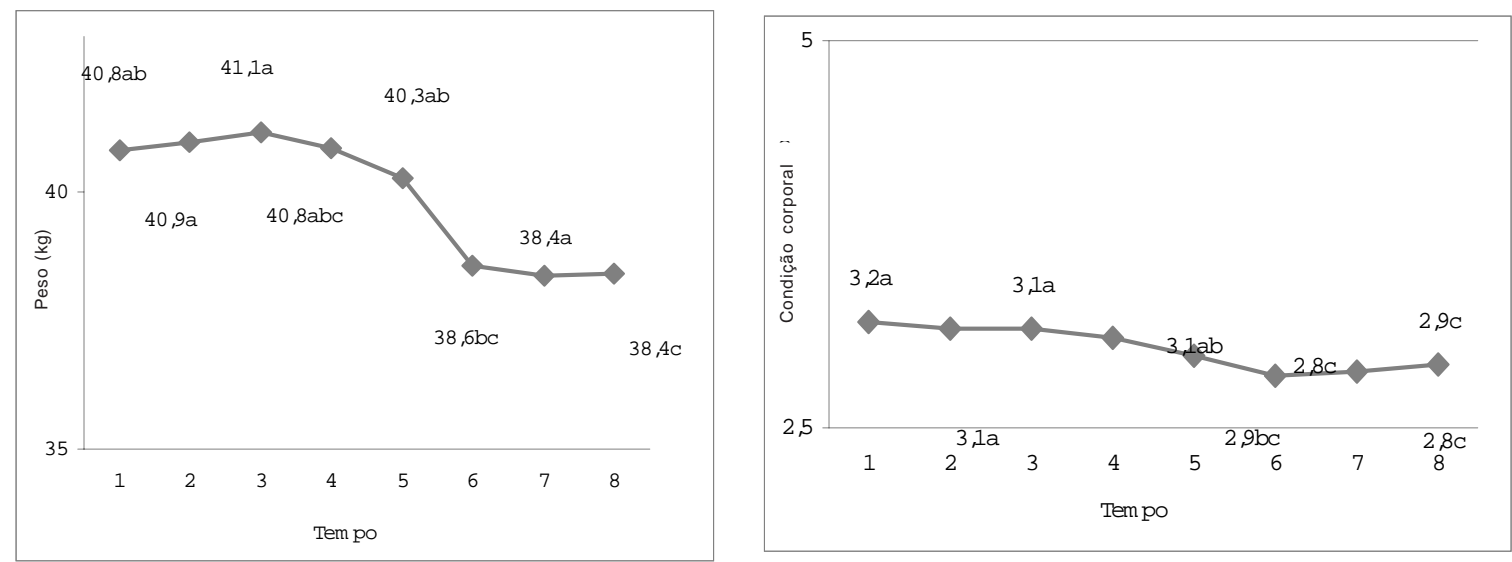

Figura 2: Peso e escore corporal de ovelhas primíparas e pluríparas da raça Santa Inês, durante o período de lactação, com mamada controlada e criadas no município de Igarapé-Açú, estado do Pará. Agosto a outubro de 2009. T1: do parto ao 1o dia do pós-parto; T2: do 2o ao 40 dia do pós-parto; T3: do 5o ao 70 dia do pós-parto; T4: do 8o ao 14을 dia do pós-parto; T5: do 15 ao 29을 dia do pós-parto; T6: do 30 ao 44 dia do pós-parto; T7: do 45 ao 59o dia do pós-parto e T8: acima de 60 dias de pós-parto. Letras diferentes na mesma variável indicam diferença significativa pelo teste de Tukey a $5 \%$.

Ao se analisar os valores séricos de proteína total e de albumina das ovelhas estudadas durante o período de lactação (Figura 3) verificou-se que os valores para a proteína total estão dentro dos intervalos de referência descritos por
A baixa concentração de fósforo $(\mathrm{P})$ no momento do parto (Figura 4) pode ter refletido a ação do paratormônio (PTH) para o incremento da concentração de cálcio, e simultaneamente induzir, por meio de mecanismos renais, 

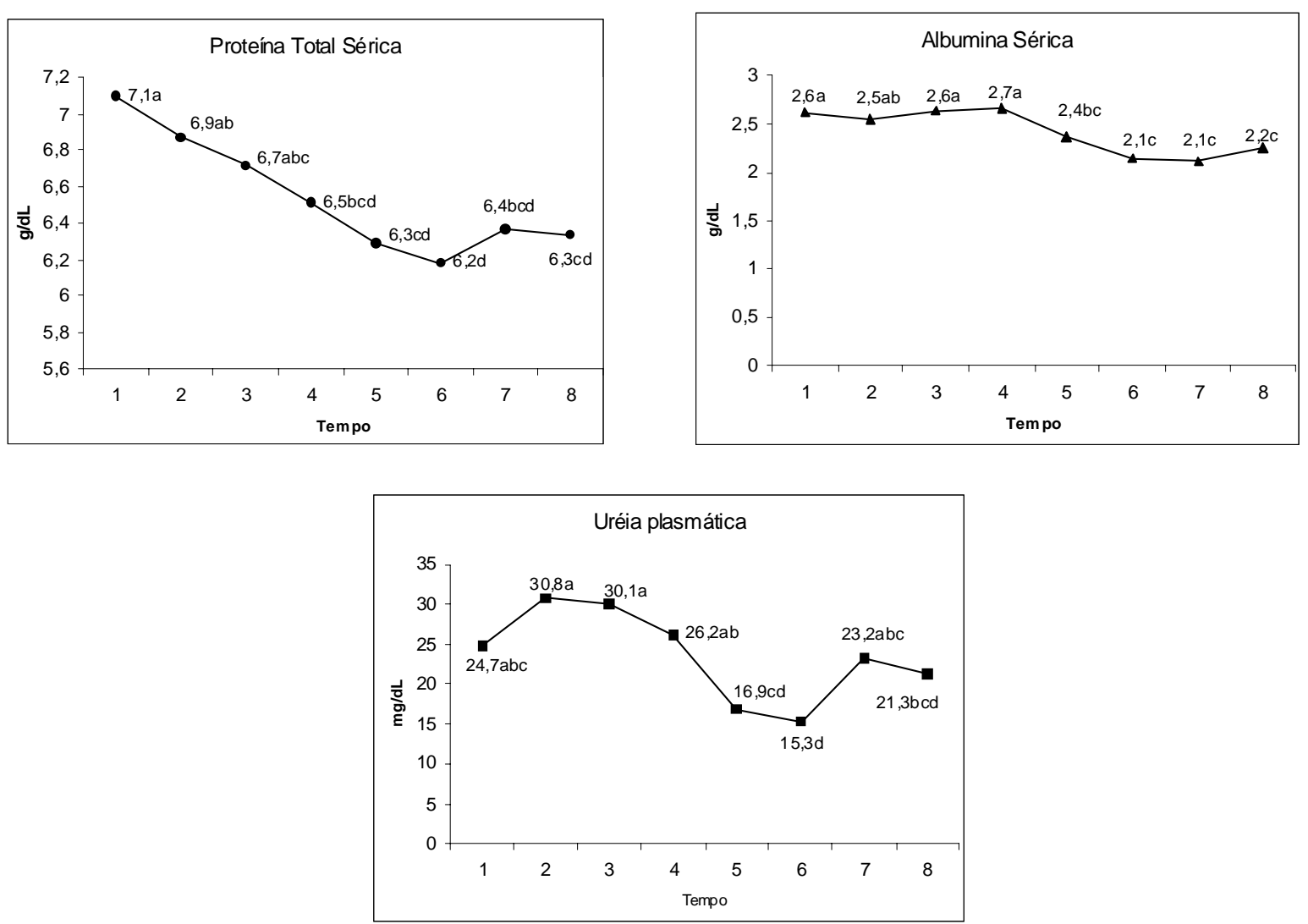

Figura 3: Proteína total, albumina e ureia no sangue de ovelhas primíparas e pluríparas da raça Santa Inês, durante o período de lactação, com mamada controlada e criadas no município de Igarapé-Açú, estado do Pará. Agosto a outubro de 2009.

a,b,c Letras diferentes na mesma variável indicam diferença significativa pelo teste de Tukey a $5 \%$.
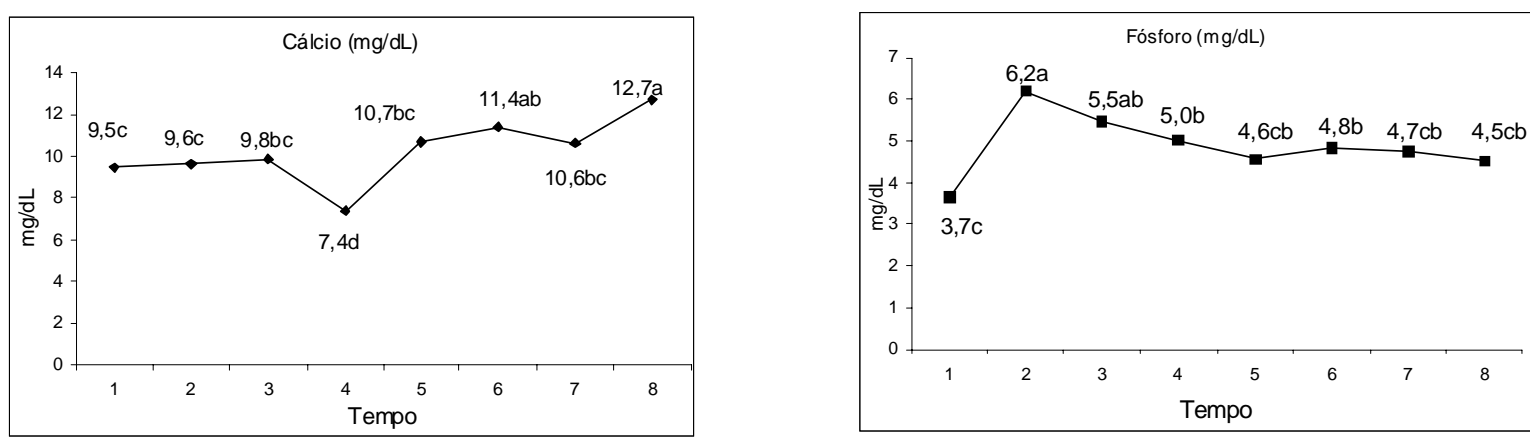

Figura 4: cálcio e fósforo de ovelhas da raça Santa Inês de acordo com o período de lactação, com mamada controlada e criadas no município de Igarapé-Açú, estado do Pará. Agosto a outubro de 2009.

a,b,c Letras diferentes na mesma variável indicam diferença significativa pelo teste de Tukey a $5 \%$.

à eliminação de fosfato conforme ressaltam Payne et al. (1970). Baixos valores também foram encontrados no final da lactação traduzindo o desgaste metabólico pela produção do leite (Rajaratne et al., 1990). Durante todo o período de lactação, os valores de $\mathrm{P}$ mantiveram-se dentro dos valores de referência estipulados por Gonzalez et al. (2000), compreendido no intervalo de 3,09 a $6,19 \mathrm{mg} / \mathrm{dL}$.

Ribeiro et al. (2003), a partir do estudo do perfil metabólico de borregas mantidas no campo nativo no estado do Rio Grande do Sul, demonstraram que os aportes nutricionais não eram adequados para garantir um correto balanço nutrição-crescimento, sendo necessário estudar o conteúdo de nutrientes nas forragens para poder fazer recomendações pertinentes sobre a forma de corrigir deficiências. Rabassa et al. (2009) também encontraram desequilíbrio nutricional em ovelhas pluríparas mantidas em campo nativo no Rio Grande do Sul durante o período de outono/inverno.

As modificações de cálcio e fósforo traduziram as modificações fisiológicas metabólicas relacionadas com o período do pós-parto e da lactação, porém, os resultados encontrados para o escore corporal, o volume globular, a hemoglobina, a albumina sérica e a ureia plasmática apontaram para a 
necessidade de pequenos ajustes dos nutrientes na ração, pois, associados ao da forrageira ainda promoveram ligeiros decréscimos nos indicadores metabólicos.

\section{Globulina, glicose e magnésio}

As concentrações de globulina sérica das ovelhas primíparas foram diferentes de ovelhas pluríparas durante todo o período de lactação estudado (Tabela 2). Nos momentos próximos ao parto, as ovelhas primíparas apresentaram um valor médio de gobulina sérica inferior ao do grupo de pluríparas. Esse comportamento pode ter caracterizado a baixa mobilização imunológica para a formação do colostro na primeira cria. De acordo com Machado Neto et al. (1995), a demanda para produção do colostro em ovelhas de mais de uma lactação é maior, visto a maior produção garantida pelo aumento no número de células secretoras, e por isso, a concentração de globulinas é incrementada na corrente sanguínea a fim de suprir essa necessidade.

Os valores de glicose plasmática encontraram-se dentro dos valores de referência definidos por Kaneco, Harvey e Bruss (1997), de 50 a 80 mg/dL porém do parto ao período imediato após o parto, as ovelhas primíparas tiveram valores de glicose mais elevados do que as ovelhas pluríparas. Esses resultados parecem comprovar que o estresse do parto é mais acentuado em ovelhas de primeira cria e provocam modificações mais intensas sob o ponto de vista metabólico e energético.

As ovelhas primíparas apresentaram uma concentração sérica de magnésio inferior em momentos diferenciados como no parto, no pique da lactação e no final da lactação àquela apresentada por ovelhas pluríparas (Tempos 1, 3, 5, 6 e 7) momentos que caracterizam desgaste de energia (Gonzalez et al., 2000). Esses valores, porém encontram-se dentro dos valores da normalidade descritos por Gonzalez et al. (2000), que varia de 1,70 a 2,67 mg/dL .

\section{Betahidroxibutirato}

O betahidroxibutirato ( $\mathrm{BHB}$ ) plasmático não apresentou diferenças em função do grupo, do tempo ou mesmo na interação das duas fontes de variação (Tabela 1). A média encontrou-se dentro dos valores de referência citados por Kaneco, Harvey e Bruss (1997).

De acordo com Gonzalez et al. (2000), em momentos de diminuição acentuada da glicemia há um aumento considerável no grau de gliconeogênese e em alguns casos, o desenvolvimento da cetose, podendo ser observado um aumento nos níveis plasmáticos de $\mathrm{BHB}$ e demais corpos cetônicos (acetoacetato e acetona). No presente experimento, evidenciou-se um aporte nutricional deficiente, porém, não sucifiente para gerar uma maior mobilização de gorduras de forma a elevar o BHB sub ou clinicamente.

\section{Conclusões}

As ovelhas lactantes possuem necessidades metabólicas distintas no início, no pico e no final da lactação.

A evolução dos índices produtivos encontrados nas ovelhas durante o período experimental não foram condizentes com um manejo nutricional apropriado.

O perfil metabólico é efetivo na detecção de distúrbios orgânicos e, portanto é uma excelente ferramenta para controle e adequação do manejo zootécnico do rebanho.

A técnica FAMACHA e a utilização do escore de condição corporal são indicadores eficientes e de fácil acesso aos produtores que podem ser trabalhadas na rotina e auxiliar no desempenho produtivo do animal.

Tabela 2: Media e desvio-padrão da globulina no soro sanguíneo de ovelhas primíparas e pluríparas, durante o período de lactação, criadas no município de Igarapé-Açú, Estado do Pará

\begin{tabular}{|c|c|c|c|c|c|c|}
\hline \multirow[t]{2}{*}{$\mathrm{T}$} & \multicolumn{2}{|c|}{ Globulina (mg/dL)) } & \multicolumn{2}{|c|}{ Glicose $(\mathrm{mg} / \mathrm{dL})$} & \multicolumn{2}{|c|}{ Magnésio (mg/dL) } \\
\hline & Primípara & Plurípara & Primípara & Pluripara & Primípara & Plurípara \\
\hline 1 & $3,92^{\mathrm{abB}} \pm 0,31$ & $5,04^{\mathrm{aA}} \pm 0,29$ & $79,50^{\mathrm{a} A} \pm 7,05$ & $52,10^{\mathrm{bB}} \pm 6,65$ & $2,49^{\mathrm{ab}} \pm 0,14$ & $3,62^{\mathrm{aA}} \pm 0,28$ \\
\hline 2 & $3,92^{\mathrm{abA}} \pm 0,27$ & $4,73^{\mathrm{abA}} \pm 0,23$ & $56,50^{\mathrm{bA}} \pm 2,43$ & $60,40^{\mathrm{abA}} \pm 4,42$ & $2,17^{\mathrm{abA}} \pm 0,13$ & $2,32^{\mathrm{dA}} \pm 0,10$ \\
\hline 3 & $3,89^{\mathrm{abA}} \pm 0,32$ & $4,31^{\mathrm{bA}} \pm 0,23$ & $63,20^{\mathrm{abA}} \pm 4,78$ & $66,65^{\mathrm{abA}} \pm 6,05$ & $1,84^{\mathrm{bB}} \pm 0,07$ & $2,38^{\mathrm{cdA}} \pm 0,15$ \\
\hline 4 & $3,50^{\mathrm{bA}} \pm 0,22$ & $4,21^{\mathrm{bA}} \pm 0,35$ & $64,20^{\mathrm{abA}} \pm 3,84$ & $64,90^{\mathrm{abA}} \pm 4,86$ & $2,20^{\mathrm{abA}} \pm 0,11$ & $2,40^{\mathrm{cbdA}} \pm 0,13$ \\
\hline 5 & $3,74^{\mathrm{abA}} \pm 0,34$ & $4,15^{\mathrm{bA}} \pm 0,45$ & $68,90^{\mathrm{abA}} \pm 4,20$ & $76,50^{\mathrm{aA}} \pm 8,43$ & $2,41^{\mathrm{abB}} \pm 0,24$ & $3,00^{\mathrm{bA}} \pm 0,35$ \\
\hline 6 & $3,98^{\mathrm{abA}} \pm 0,29$ & $4,10^{\mathrm{bA}} \pm 0,31$ & $62,90^{\mathrm{abA}} \pm 3,14$ & $67,10^{\mathrm{abA}} \pm 5,17$ & $1,89^{\mathrm{bB}} \pm 0,15$ & $2,35^{\mathrm{CdA}^{-}} \pm 0,17$ \\
\hline 7 & $4,22^{\mathrm{aA}} \pm 0,37$ & $4,27^{\mathrm{bA}} \pm 0,31$ & $60,30^{\mathrm{bA}} \pm 1,61$ & $63,45^{\mathrm{abA}} \pm 1,78$ & $1,98^{\mathrm{abB}} \pm 0,14$ & $2,53^{\mathrm{cbdA}} \pm 0,16$ \\
\hline 8 & $3,97^{\mathrm{abA}} \pm 0,35$ & $4,22^{\mathrm{bA}} \pm 0,23$ & $56,60^{\mathrm{bA}} \pm 2,0$ & $52,30^{\mathrm{bA}} \pm 1,53$ & $2,55^{\mathrm{aA}} \pm 0,07$ & $2,93^{\mathrm{cbA}} \pm 0,21$ \\
\hline
\end{tabular}

(T) Tempos 1: parto a 1 dia pós-parto; 2: 2 a 4 dias pós-parto; 3: 5 a 7 pós-parto; 4: 8 a 14 dias do pós-parto; $5: 15$ a 29 dias do pós-parto; 6: 30 a 44 dias do pós-parto; 7: 45 a 59 dias do pós-parto; 8: e" 60 dias do pós-parto

ab Letras diferentes na mesma coluna indicam diferença significativa pelo teste de Tukey a $5 \%$ ao longo do tempo.

${ }^{A B}$ Letras diferentes na mesma linha indicam diferença significativa pelo teste de Tukey a $5 \%$ ao entre os grupos em cada tempo estudado.

\section{Referências}

ALENCAR, N.X.; KOHAYAGAWA, A.; RODRIGUES, C.F.C.; CIARLINI, P.C.; RAMOS, P.R.R.; CAMPOS, K.C.H. Proteinograma e exame coproparasitológico de ovelhas das raças Ideal e Suffolk durante o periparto. Revista Brasileira de Ciência Veterinária, v. 14, n. 2, p. 111-116, 2007.
ARCO JORNAL. Estados se mobilizam para abate ovino. v. 3, n. 12, p. 7, 2009.

BRITO, M.A.; GONZÁLEZ, F.D.; RIBEIRO, L.A., CAMPOS, R., BARBOSA, P.R.; BERGMAN, G. Composição do sangue e do leite em ovinos leiteiros do sul do Brasil: variações na gestação e lactação. Ciência Rural, v. 36, n. 3, p.1-7, 2006. 
CONTRERAS P.; MOLLER, I.;WITTWER F.; TADICH N. Concentraciones sanguíneas de glucosa, colesterol, cuerpos cetónicos y actividad de aspartato aminotransferasa en ovejas con gestacíon única y gemelar en pastoreo rotacional intensivo. Archivos de Medicina Veterinaria, v. 22, p. 65-69, 1990.

COSTA FILHA, C.L. Avaliação das potencialidades das terras para a determinação de zonas agroecológicas, no município de IgarapéAçu - Pará. 120 p. 2002. Dissertação de Mestrado em Ciência do Solo - Universidade Federal Rural da Amazônia, Belém, 2002.

DEL VALLE, J.; WITNER, F.; HERVÉ, M. Estudio de los perfiles metabólicos durante los períodos de gestación y lactancia en ovinos Romney. Archivos de Medicina Veterinaria, v. 15, p. 65-72, 1983.

FAEPA. 2008. Projeto da ACCOPA e SINDICCOPA propõe o crescimento da ovinocultura. (http://www.faepanet.com.br/index.php?option= com_content\&view=article\&id=119\%3Aprojeto-da-accopa-esindiccopa-propoe-crescimento-da-ovinocultura\&ltemid=55). Acesso em 04/01/2010.

GREENWOOD, P.L.; HUNT, A.S.; HERMANSON, J.W.; BEL, A.W. Effects of birth weight and post natal nutrition on neonatal sheep II. skeletal muscle growth and development. Journal of Animal Science, n. 78, 2000.

GONZALEZ, F.H.D.; BARCELLOS, J.; PATIÑO, H.O.; RIBEIRO, L.A. Perfil metabólico em ruminantes. Seu uso em nutrição e doenças nutricionais. Porto Alegre: UFRGS, 2000, $108 \mathrm{p}$.

HÜBNER C. H.; PIRES, C. C.; GALVANI, D. B.; CARVALHO, S.; JOCHINS F.; WOMMER, T.P.; GASPERIN. B.G. Comportamento ingestivo de ovelhas em lactação alimentadas com dietas contendo diferentes níveis de fibra em detergente neutro. Ciência Rural, Santa Maria, v.38, n. 4, p.1078-1084, 2008.

JAIN, N.C. Essencials of veterinary hematology. Philadelphia: Lea e Febiger, 1993, $417 p$.

KANEKO, J.J.; HARVEY, J.W.; BRUSS, M.L. Clinical biochemnistry of domestic animals. San Diego: Academic Express, 1997, 9321 p.

MACHADO NETO, R.; PRADO, G.V.B.; BESSI, R.; HATTNHER, F.L. Flutuação das proteínas séricas em vacas primíparas e multíparas no período pré-parto. Science Agriculture, v. 52, n. 1, p. 158-160, 1995.

MOLENTO, M.B.; TASCA, C.; GALLO, A.; FERREIRA, M.; BONONI, R.; STECCA, E. Método Famacha como parâmetro clínico individual de infeccção por Haemonchus contortus em pequenos ruminantes. Ciência Rural, v. 34, n. 4, p. 1139-1145, 2004.
MOURA FILHO, J.; RIBEIRO, E. L. A.; SILVA, L.D.F.; ROCHA, M.A., MIZUBUTI, I.Y.; PEREIRA, E.S.; MORI, R.M. Suplementação alimentar de ovelhas no terço final da gestação: desempenho de ovelhas e cordeiros até o desmame: Ciências Agrárias, v. 26, n. 2, p. 257-266, 2005.

MUNDIM, A.V.; COSTA, A.S.; MUNDIM, S.A.P.; GUIMARÃES, E.C.; ESPINDOLA, F.S. Influência da ordem e estágio da lactação no perfil bioquímico sanguíneo de cabras da raça Saanen. Arquivos Brasileiros de Medicina Veterinária e Zootecnia, v. 59, p. 306-312, 2007.

PAYNE, J.M.; SALLY, M.; DEW, M.; MANSTON, R.; FAULKS, M. The use of the metabolic profiles test in dairy herds. Veterinary Record, v. 87, p. $150-158,1970$.

PEIXOTO, L.A.O.; OSÓRIO, M. T. M. Perfil metabólico proteico e energético na avaliação do desempenho reprodutivo em ruminantes. Revista Brasileira de Agrociência, Pelotas, v. 13, n. 3, p. 299-304, 2007.

RABASSA, V.R.; TABELEÃO, V.C.; SCHNEIDER, A. et al. Avaliação metabólica de ovelhas de cria mantidas em campo nativo durante o período de outono/inverno. Revista Brasileira de Agrociência, Pelotas, v. 15, n. 1-4, p. 125-128, 2009.

RAJARATNE, A.A.J.; SCOTT, D.; BUCHAN, W.; DUNCAN, A. The effect of variation in dietary protein or mineral supply on calcium and phosphorus metabolism in lactating ewes. British Journal of Nutrition, v. 64, p. 147-160, 1990.

RIBEIRO, L.A.O.; GONZÁLEZ, F.H.D.; CONCEIÇÃO, T.R.;BRITO, M.A.; LA ROSA, V.L.; CAMPOS, R. Perfil metabólico de borregas Corriedale em pastagem nativa do Rio Grande do Sul. Acta Scientiae Veterinariae, Porto Alegre, v. 31, p. 167-170, 2003.

RIBEIRO, L.A.O.; MATTOS, R.C.; GONZALEZ, F.H.D.; WALD, V.B.; SILVA, M.A.; LA ROSA, L.V. Perfil metabólico de ovelhas Border Leicester x Texel durante a gestação e lactação. Revista Portuguesa de Ciências Veterinárias, v. 99, n.551, p. 155-159, 2004.

SILVA, F.L.R.; LÔBO, R.N.B. Potencial Leiteiro de Cabras Mestiças no Estado do Ceará. Comunicado Técnico da Embrapa, n. 59, 2003.

SUITER, J. Body condition score of sheep and goat. Farm Note, n. $69,1994$.

UENO, H. Manual para diagnóstico das helmintoses de ruminantes. 4. ed. Japan: International Cooperation Agency, 1998. 143 p. 